\title{
PREDICTING ACCEPTANCE OF MODERN MYTHS ABOUT SEXUAL AGGRESSION
}

\begin{abstract}
Sexual violence is an important public health problem that affects the well-being of a large proportion of adolescents. The empirical studies indicated that the attitudes towards sexual violence are strong predictors of the likelihood of both perpetrating sexually aggressive acts and being victimized. That is why comprehensive sexuality education, among the other objectives, makes remarkable efforts to inculcate negative attitudes towards violence, particularly sexual, in children and adolescents. This study makes an attempt to shed light on the relation of sexual-violence supportive attitudes, gender norms conformity, and specific knowledge about sexual violence in acceptance of modern myths about sexual violence. Its main objective is to inform curricula developers what are the complex links among these features in order to help them create and deliver efficient programs in comprehensive sexuality education. The study was carried out with 483 participants (43,6\% males), at the age range from 18 to $24(M=21,6, S D=3,0)$. The results suggest that conformity to certain masculine gender norms in addition to sexist attitudes can help in predicting the endorsement of modern myths about sexual violence. Contrary to the expectations, it has been found that the specific knowledge about sexual violence does not contribute significantly to predicting the criterion variable. Based on the study findings, it is suggested that much more than providing students with relevant information, sexuality education should address and highlight the need for introducing transformative gender identities/roles alongside working on de-constructing gender discrimination.
\end{abstract}

Key words: modern myths about sexual violence, gender norms, sexism, sexuality education

\section{INTRODUCTION}

Globally, an estimated one in three women and girls worldwide have been subjected to relationship violence or non-partner sexual violence, or both, at least once in their life, making gender-based violence one of the most widespread human rights violations. Gender violence starts early: one-quarter of adolescent girls aged 15 to 24 who have been in a relationship report at least one experience of violence committed by their intimate partner. In the same age group, an estimated $6 \%$ are victims of non-partner sexual violence at least once 
in their lifetime (WHO, 2021). This number is very likely to be much higher, especially in underdeveloped countries, having in mind the societal and psychological barriers that victims face in reporting it.

Nearly all recommendations and strategies for the prevention of gender violence recognize the importance of introducing systematic and inclusive school-based programs designed to challenge discriminatory attitudes and beliefs, promote gender sensitivity and relationships based on equality, and address all forms of gender-based discrimination. Past evaluation research has recommended that education in human sexuality can lead towards a decrease in rape-supportive ideology in both males and females (Dallager \& Rosen, 1993; Lonsway, 1996).

In the last decade, Comprehensive Sexuality Education (CSE) has been internationally recognized as a key entry point for promoting gender equality and the rights of young people, in that way playing an important role in the battle against sexual and gender-based violence. This program, supported by several UN agencies, provides teenagers with opportunities to acquire broad, accurate, science-based, and age-appropriate information on sexuality, thus helping them in making informed choices for living safe, productive, fulfilling life free from different health-related risks. It aims to equip children and young people with knowledge, skills, attitudes, and values that will empower them to understand the different ways in which gender norms can influence inequality, and how these inequalities can prevent the efforts to overcome issues such as the transmission of sexual infections, teenage pregnancies, and vulnerability to gender-based violence.

There is a solid body of evidence showing that CSE, especially when it is school-based, has positive effects, including increasing young people's knowledge and improving their attitudes related to accepting sexual rights and reducing gender stereotypes (eg. Fonner et al., 2014; Kenig \& Kostovski, 2019; Kirby, 2008; UNESCO, 2016). Makleff and colleagues (2019) recently concluded that CSE could help in the prevention of and response to intimate partner violence, in part by facilitating the process of changing attitudes and gendered social norms. In their experimental study, they found statistically significant improvements in two of the three knowledge questions about violence after students' exposure to 20-hour SCE training. Intriguingly, the quantitative analysis indicated a change in only several attitudes on gender relations and did not detect a significant shift in attitudes about the acceptability of violence. Their qualitative findings point toward the ways in which CSE appears to contribute to the identified changes. The major contribution was assigned to the possibility of engaging in critical reflection about the effects of the gendered social norms upon violence. This participatory approach further enabled the participants to know and identify types of partner violence and they also learned to seek help and to assertively communicate their experiences and feelings.

Despite wide recognition of the need for sexuality education, there is less clarity about what are the most efficient ways of its implementation, espe- 
cially in a context where it tackles culturally sensitive issues or faces opposition (UNESCO, 2015). This is why any kind of empirical evidence on how to set the standards of delivering the core CSE themes is more than welcome. The leading question of this research is to identify whether, in addition to the role of the set of sexual violence-related attitudes (adversarial sexual beliefs, hostile and benevolent sexism), the critical conformity to gender norms and specific knowledge on sexual violence play role in the acceptance of modern myths of sexual aggression.

\section{Relevant research}

Rape myths are widely spread beliefs that function as a mechanism where victims of sexual violence are accused of their victimization (Ryan, 2011). Although over the past decades rape myths that blatantly blame victims and rationalize the aggression of sexual perpetrators have become less socially acceptable, many of the beliefs that women provoked the assault or that the violence is somehow justifiable or even exaggerated and false are still existent in somewhat more subtle wordings (Hockett, Saucier, \& Badke, 2016; Saucier et al., 2015). Using the framework from social psychological and feminist theory, Burt (1980) was among the first researchers who revealed empirical evidence that high respondents' acceptance of rape myths, might be predicted on the basis of higher sex-role stereotyping, adversarial sexual beliefs, and acceptance of interpersonal violence.

The consequences of high endorsement of rape myth acceptance are severe, which provide additional support of why it needs to be examined together with multiple underwriting variables. Thus, attitudes towards women and gender equality have justifiably been of central concern in research regarding gender-based violence, particularly sexual violence. They play a crucial part in disinhibiting the perpetration of this violence, and in community reactions to it. In studies about the effect of sexist beliefs toward women, both hostile and benevolent sexism were found as significant correlates (e.g. Kenig, 2015) of either rationalizing sexual violence or perceiving it as a deserved reaction to victims transgressing relevant gender norms (Abrams et al., 2003; Canto, Perles and Martin, 2014; Rollero and Tartallia, 2019).

There is a consistent evidence of an association between violence-supportive beliefs and values and the perpetration of violent behavior, at both individual and community levels. Adolescents and adult men who accept rape-supportive beliefs are more likely to have been sexually violent or report proclivity to rape (Anderson, Simpson-Taylor, \& Hermann, 2004; Bohner et al., 2005; Chirroro, 2004).

Rigid traditional gender norms are also considered as being a reliable pillar of sexual violence reinforcement. It has been well documented that men with more traditional gender-role attitudes are more likely to perform gender-based violence (e.g. Chapleau, Oswald, \& Russell, 2007; Heise, 1998; Her- 
rero, 2017; Santana et al., 2006; O'Neil \& Harway, 1997), whereas women who conform to traditional gender-role attitudes are prone to report abuse by their partners less (eg. Harris, Firestone, \& Vega, 2005). Research grounded in the theoretical framework of ambivalent sexism proposes that for both sexes, sexist attitudes acceptance is associated with higher rape myth acceptance and that individuals with a more traditional understanding of gender roles are more likely to blame the victim for the sexual assault than those with non-traditional gender views (Chapleau et al.,2007; Rollero \& Tartaglia, 2019).

An important advance in both conceptualizing and measuring acceptance of sexual violence was the development of the Acceptance of Modern Myths about Sexual Aggression Scale, aimed to address the concerns that were raised out of experiences with previous measures of rape myths endorsement, mainly their susceptibility to politically correct answers. The authors of this relatively new scale (Gerger et al., 2013) incorporated more subtle item wording to covert beliefs about rape, its victims, policies regarding sexual assault, and the understanding of the roots of sexual coercion. They also argued that the previous instruments, particularly the Illinois Rape Myths Acceptance Scale does not distinguish sufficiently rape myths from pro-violence attitudes and in order to avoid socially desirable answers, proposed items that take into account the insights from exploring modern sexism and racism. In several studies, this measure is reported to be highly reliable and the evidence for its concurrent and predictive construct validity is quite well established (Hantzi, et al, 2015; Megias et al, 2011). It correlates highly with Adversarial Sexual Beliefs, Sex Role Stereotyping, Sexual Conservatism, and Gender-Specific System Justification measures, as well as with knowledge about sexual reproduction (Aronowitz et al., 2012; Watson, 2016).

Understandably, attitudes that support sexual violence, especially rape myths and sexist beliefs, along with the traditional gender norms that are the supportive value system for endorsing such attitudes and expressing them behaviorally, have been a key target for change within various education campaigns or programs aimed at preventing gender-based violence. The answer to the question of whether lower levels of conformity to traditional gender norms and the acquisition of specific knowledge about sexual violence, hopefully, might also help in informing the sex education curricula designers and the teachers who implement the program in their efforts to fight against acceptance of sexual violence myths.

\section{METHOD}

\section{Sample}

The sample comprised 483 participants (43,6\% males), all ethnic Macedonians, who live in 17 different towns/cities in the country ( $42 \%$ from Skopje). Their age range was from 18 to $24(M=21,6, S D=3,0)$. The majority have complet- 
ed secondary school $(78,2 \%)$. Almost half $(47,9 \%)$ are in a romantic relationship, $36 \%$ are single and the rest did not report their status.

\section{Instruments}

The Acceptance of Modern Myths of Sexual Aggression (AMMSA) is a 30 item scale that measures the approval of more subtle expressions of beliefs that support sexual aggression by minimizing it or attributing the blame on victims or certain contexts. Thus, compared with traditional rape myth acceptance scales, the averages of AMMSA scores derived from several cross-cultural studies, are much higher and their distributions are not heavily skewed (Gerger et al., 2007).

The Adversarial Sexual Beliefs Scale (ABS) was used to assess whether the beliefs on heterosexual interpersonal relations are based on acceptance of interpersonal violence and gender role stereotyping as unavoidable. It measures the extent to which individuals endorse antagonistic sexual roles between females and males as being a "normal" part of the male to female relations The authors noted that in developing the items, they took care to ensure that the content was focused primarily on the nature of the relationship between the sexes, rather than on gender stereotypes of either sex (Lonsway \& Fitzgerald, 1995).

The benevolent and hostile sexism were assessed by using the Ambivalent Sexism Inventory (ASI) developed by Glick \& Fiske (1997). Hostile sexism reflects a clear negative reaction toward women, who are perceived as challenging men's power and status or as manipulating men sexually in order to gain control over them. Benevolent sexism, on the other hand, has a form of seemingly positive, helping, and prosocial but actually patronizing attitudes toward women. It is a 22 -item (11 items for each subscale) self-report inventory. Higher scores suggest a higher degree of acceptance of either benevolent or hostile sexism.

Conformity to gender norms has been measured by two complementary instruments, each administered only to participants from the corresponding sex: Conformity to Feminine Norms Inventory (CFNI-45) and Conformity to Masculine Norms Inventory (CMNI-46). Both instruments are modifications of the longer original versions developed by Parent and Moradi (2010, 2010b). According to the authors, these instruments assess normative masculinity and femininity broadly, by addressing assessing behavioral, affective, and cognitive conformity to gender norms Mahalik et al. (2003). Respondents indicate their agreement with statements on a 5-point scale of agreement and higher scores mean stronger conformity to the rules and standards expected from the two genders. CMNI comprises 9 subscales: Competition, Emotional Control, Risk-taking, Violence, Playboy, Self-reliance, Primacy of Work, Power over Women Heterosexual Self-presentation.

CFNI's factor structure includes 9 dimensions organized in subscales. Sample items on the CFNI 9 subscales include: "I am always trying to lose weight" (Thinness scale), "I always downplay my achievements" (Modesty 
scale), "I enjoy spending time to make my living space look nice" (Domestic scale), "It is important to look physically attractive in public" (Invest in Appearance scale), "I believe that my friendships should be maintained at all costs" (Kind in Relationships scale), "Being nice to others is extremely important" (Sweet and nice), "Taking care of children is extremely fulfilling"(Care for Children scale), "I would feel guilty if I had a one-night stand" (Sexual Fidelity scale), and "Having a romantic relationship is essential in life" (Romantic Relationship scale).

The familiarity with facts about sexual violence and how it might be demonstrated behaviorally was measured by a Knowledge about sexual violence questionnaire that contains 5 questions relevant to the topic (for example, which is a minimal sexual consent age, or what among three described behaviors indicate sexual harassment). They were developed specifically for the purpose of this study. All of them were multiple-choice questions, with three alternatives and one correct answer. Each correct answer was worth one point, whereas no points were deducted for the incorrect answers.

\section{Procedure}

All participants took part in this study voluntarily, based on previously given informed consent. Their participation did not involve any kind of compensation. Participants responded to the described instruments online, after receiving them at their personal e-mail addresses. The data gathering process took place in April 2021.

\section{Statistical methods}

In addition to descriptive statistics and internal homogeneity coefficients, the Shapiro-Wilk test was used to assess the data distributions. Gender differences in averages on the attitudes and knowledge were tested with a t-test for independent groups. A hierarchical multiple regression model was used to analyze the effect of predictor variables on the endorsement of modern myths about sexual aggression. The analysis was performed by statistical software SPSS 20.

\section{RESULTS}

The means, standard deviations, the coefficients of internal consistency, and the Shapiro-Wilk test values for the included instruments are presented in Table 1. All instruments have satisfactory reliability coefficients, except for the test on information whose internal homogeneity, somewhat below the critical value of $\alpha=, 60$ might be considered acceptable taking into account the number of items. 
Table 1.

Descriptives for modern sexual violence myths acceptance, adversarial sexual beliefs, benevolent and hostile sexism, conformity to gender norms, and information about sexual violence

M range $\mathrm{N} \quad \mathrm{SD}$ a Shapiro-

\begin{tabular}{|c|c|c|c|c|c|c|}
\hline $\begin{array}{l}\text { AMMSA- Acceptance of Modern Myths } \\
\text { about Sexual Aggression }\end{array}$ & 3,53 & $1-7$ & 483 & 1,3 & ,92 & 1,00 \\
\hline ABS- The Adversarial Sexual Beliefs Scale & 2,81 & $1-5$ & 483 & ,90 & 80 & $98^{* *}$ \\
\hline BS-Benevolent sexism & 3,30 & $1-5$ & 483 & ,70 & ,72 & ,98 \\
\hline HS-Hostile sexism & 2,76 & $1-5$ & 483 & ,87 & ,85 & ,99* \\
\hline Knowledge about sexual violence & 2,5 & $0-5$ & 483 & 1,03 &, 55 &, $92^{* *}$ \\
\hline CFNI 45- Conformity to Feminine Norms & 3,31 & $1-5$ & 271 & ,39 & ,62 & $99^{*}$ \\
\hline $\begin{array}{l}\text { CMNI 46- Conformity to Masculine } \\
\text { Norms }\end{array}$ & 2,65 & $1-5$ & 211 & 47 & ,73 & 1,00 \\
\hline
\end{tabular}

Note. All arithmetic means, and standard deviations are transformed on a scale in accordance with the number of points on the Lickert scale. The exception is the variable on knowledge about sexual violence.

${ }^{* *} p<, 01 ;{ }^{*} p<, 05$

Table 2 shows the means and standard deviations of the included variables segregated by gender, the t values, and Cohen's $d$ values. Except for the knowledge on sexual violence, females and males differ significantly regarding all other measured variables. Male participants were significantly higher in acceptance of modern myths, hostility toward women (very large effect size), and adversarial beliefs (medium effect size) whereas female participants were higher than their male counterparts in accepting benevolent sexism (small effect size).

Table 2.

Gender differences in averages on predictors: attitudes and knowledge

\begin{tabular}{|c|c|c|c|c|c|c|c|}
\hline & $\mathrm{M}$ & SD & $\mathrm{M}$ & SD & $\mathrm{F}$ & $\mathrm{t}$ & $\mathrm{d}^{ц}$ \\
\hline & \multicolumn{2}{|c|}{ Female part. } & \multicolumn{2}{|c|}{$\begin{array}{l}\text { Male } \\
\text { part. }\end{array}$} & & & \\
\hline $\begin{array}{l}\text { Acc. of modern myths abt. } \\
\text { sexual aggression }\end{array}$ & 3,11 & 90 & 3,97 & ,98 & 0,44 & $10,04^{* *}$ & ,91 \\
\hline Benevolent sexism & 3,36 & ,73 & 3,21 & ,64 & 2,87 & $-2.40^{*}$ & 21 \\
\hline Hostile sexism & 2,39 & ,77 & 3,23 & ,74 & 1,48 & $11.94^{* *}$ & 1,20 \\
\hline Adversarial heterosexual beliefs & 2,68 & ,85 & 2,98 & ,93 & 1,86 & $3,69^{* *}$ &, 34 \\
\hline $\begin{array}{l}\text { Knowledge about sexual } \\
\text { violence }\end{array}$ & 2,54 & 1,07 & 2,45 & ,98 & 2,60 & ,90 & l \\
\hline
\end{tabular}




\section{Table 3.}

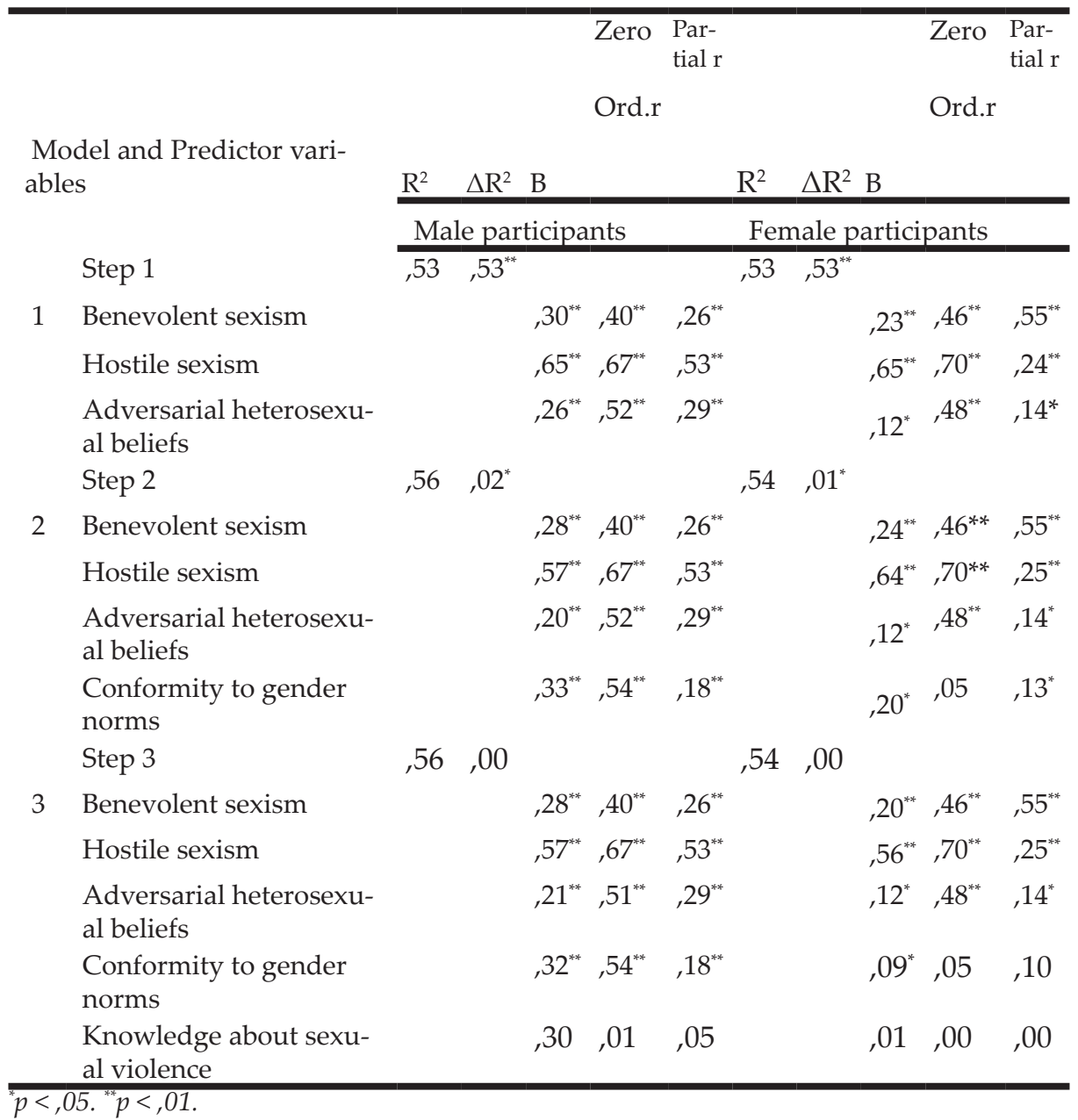

Finally, Table 4 reveals the correlations between the specific dimensions of gender norms and modern myths' acceptance. In accordance with the finding that the overall score of conformity to female gender norms is not significantly correlated to the dependent variable, none of the nine dimensions is associated with it as well. Regarding conformity to masculine norms, as could be expected, there are only four dimensions that are not connected to acceptance with the endorsement of sexual violence. Especially high likelihood to sexual aggression supportive attitudes have males who score higher on power over women and heterosexual self-presentation. 
Table 4.

\begin{tabular}{|c|c|c|c|c|c|c|c|c|}
\hline \multicolumn{9}{|c|}{ Male participants $(N=211)$} \\
\hline $\begin{array}{l}\text { Play- } \\
\text { boy }\end{array}$ & $\begin{array}{l}\text { Hetero- } \\
\text { sex. } \\
\text { Self-pres- } \\
\text { entation }\end{array}$ & $\begin{array}{l}\text { Pri- } \\
\text { macy } \\
\text { of } \\
\text { Work }\end{array}$ & $\begin{array}{l}\text { Self-re- } \\
\text { liance }\end{array}$ & $\begin{array}{l}\text { Emo- } \\
\text { tional } \\
\text { Con- } \\
\text { trol }\end{array}$ & $\begin{array}{l}\text { Power } \\
\text { over } \\
\text { Wom- } \\
\text { en }\end{array}$ & $\begin{array}{l}\text { Risk-tak- } \\
\text { ing }\end{array}$ & $\begin{array}{l}\text { Vio- } \\
\text { lence }\end{array}$ & $\begin{array}{l}\text { Com- } \\
\text { peti- } \\
\text { tion_ }\end{array}$ \\
\hline $21^{* *}$ &, $38^{* *}$ &,- 03 &, $36^{* *}$ &, 08 &, $54^{* *}$ &, $22^{* *}$ & $23^{* *}$ & ,01 \\
\hline \multicolumn{9}{|c|}{ Female participants $(N=272)$} \\
\hline & & & & & & & & $\begin{array}{l}\text { Ro- } \\
\text { man- } \\
\text { tic }\end{array}$ \\
\hline $\begin{array}{l}\text { Sweet } \\
\text { and } \\
\text { nice }\end{array}$ & $\begin{array}{l}\text { Kind in } \\
\text { rela- } \\
\text { tionsh. }\end{array}$ & $\begin{array}{l}\text { Ap- } \\
\text { pear } \\
\text { ance }\end{array}$ & $\begin{array}{l}\text { Care } \\
\text { for } \\
\text { chil- } \\
\text { dren }\end{array}$ & $\begin{array}{l}\text { Sex- } \\
\text { ual } \\
\text { fidel- } \\
\text { ity }\end{array}$ & $\begin{array}{l}\text { Domes. } \\
\text { skills }\end{array}$ & Modesty & $\begin{array}{l}\text { Thin- } \\
\text { ness }\end{array}$ & $\begin{array}{l}\text { rela- } \\
\text { tion- } \\
\text { ship }\end{array}$ \\
\hline 03 &,- 06 &,- 01 & 01 &,- 01 & ,03 & ,10 &, 04 & ,11 \\
\hline
\end{tabular}

\section{Discussion}

While there is a rich body of research on various predictors of acceptance of rape myths, the reports on the predictors of modern myths about sexual violence are yet limited. We proposed a model investigating the effect of sexist attitudes (hostile sexism, benevolent sexism, and adversarial sexual beliefs) coupled with identification with gender norms and information about sexual violence on the endorsement of myths about sexual aggression. The findings are in line with literature that has confirmed the effects of open sexism on acceptance of sexual violence (e.g., Canto et al.,2014; Fedi \& Rollero, 2016) and underline the need to focus more on the benevolent forms that justify the traditional gender roles binary (Glick et al., 2004). The effects of conformity to traditional gender roles, although very small in comparison to the set of sexist attitudes, are not irrelevant too. Contrary to our expectations, on the other hand, the results have shown that both male and female adolescents accept these contemporary myths irrespective of how well they are informed about relevant issues on this topic.

In conclusion, findings suggest that the educational programs aiming at decreasing contemporary myths about sexual violence should consider the key role of not only open hostility toward women but also the seemingly naïve benevolent beliefs and rigid gender norms as reinforcing and enhancing powers that support the sexual violence misconceptions. In addition to contents and 
pedagogical practices aimed at eliminating such sexist attitudes, programs like CSE should involve effective strategies aiming to de-construct the essentialist view that traditional gender roles are natural, unchangeable, or healthy. It is clear that special attention should be paid to raising awareness of the potential harmfulness of identifying with certain aspects of hegominic masculinity. Some of them have already been documented as risky for the individual health of young men (Kenig, 2020; Noar \& Morokoff, 2002; Reidy et al, 2016). Moreover, this study identifies an almost complementary set of dimensions of masculine norms that is dangerous in that it represents potential support for involvement in gender-based violence. It is advisable for programs aimed at reducing this type of violence, to make efforts in distinguishing these specific dimensions from the perspective of the consequences of each individual dimension. The need for dominance over women, the homosexuality disdain, the approval of violence, and even the self-reliance and tendency for risk-taking play a role in supporting sexual aggression, which is not the case with, for example, the need for competition or career primacy as dimensions of traditional masculinity.

The fact that knowledge was not detected as a significant predictor, does not inevitably exclude its importance, but inevitably leads us to the three main limitations of this research. First, it is of exploratory nature and not based on a particular theoretical model. The sample is convenient and thus potentially biased and on average, participants are in late adolescence whereas students involved in CSE programs are usually much younger. Finally, the most important limitation is the length of the questionnaire with which the knowledge about sexual violence was tested. Its length has obviously compromised both the reliability and the sensitivity of the measure and future research should make all efforts to surpass this flaw. 


\section{References}

Abrams, D., Viki, G. T., Masser, B., \& Bohner, G. (2003). Perceptions of stranger and acquaintance rape: the role of benevolent and hostile sexism in victim blame and rape proclivity. Journal of Personality and Social Psychology, 84(1), pp. 111-125.

Anderson, V. N., Simpson-Taylor, D., \& Hermann, D. J. (2004). Gender, age, and rape-supportive rules. Sex Roles: A Journal of Research, 50, pp. 7-20.

Aronowitz, T., Lambert, C., \& Davidoff, S. (2012). The role of rape myth acceptance in the social norms regarding sexual behavior among college students. Journal of Community Health Nursing, 29(3), pp. 173-182. doi: 10.1080/07370016.2012.697852 7-90.

Bohner, G., Siebler, F., \& Schmelcher, J. (2006). Social norms and the likelihood of raping: Perceived rape myth acceptance of others affects men's rape proclivity. Personality E Social Psychology Bulletin, 32(3), pp. 286-297.

Burt, M. (1980). Cultural myths and supports for rape. Journal of Personality and Social Psychology, 38, pp.217-230.

Canto, J. M., Perles, F., \& Martín, J. S. (2014). The role of right-wing authoritarianism, sexism and culture of honour in rape myths acceptance/El papel del autoritarismo de derechas, del sexism y de la cultura del honor en la aceptación de los mitos sobre la violación. Revista de Psicología Social, 29(2), pp.296-318.

Chapleau, K. M., Oswald, D. L., \& Russell, B. L. (2007). How ambivalent sexism toward women and men support rape myth acceptance. Sex Roles, 57(12), 131-136.

Chapleau, K., Oswald, D. L., \& Russell, B. L. (2008). Male rape myths: The role of gender, violence, and sexism. Journal of Interpersonal Violence, 23(5), pp. 600-615. doi: 10.1177/0886260507313529

Chiroro P, Bohner G, Viki G.T. and Jarvis C.I. (2004). Rape Myth Acceptance and Rape Proclivity: Expected Dominance versus Expected Arousal as Mediators in Acquaintance-Rape Situations. Journal of Interpersonal Violence, 19(4), pp.427-442. doi:10.1177/0886260503262081

Dallager, C. \& Rosen, L.A. (1993). Effects of a human sexuality course on attitudes toward rape and violence. Journal of Sex Education and Therapy,19, pp.193-199.

Fonner, V. A. Kevin S. Armstrong, K.S, Kennedy, C.E., O’Reilly, K.R. \& Sweat, M.D. (2014). School Based Sex Education and HIV Prevention in Lowand Middle-Income Countries: A Systematic Review and Meta-Analysis, PLoS ONE, 9 (3) p. e89692. http://doi.org/10.1371/journal.pone.0089692

Gerger, H., Gerger, H., Kley, H., Bohner, G., \& Siebler, F. (2007). The Acceptance of Modern Myths about Sexual Aggression (AMMSA) scale: Development and validation in German and English. Aggressive Behavior, 33, pp. 422-440. 
Gerger, H., Kley, H., Bohner G., Siebler, F. (2013). Acceptance of Modern Myths about Sexual Aggression (AMMSA) scale. Measurement Instrument Database for the Social Science. Retrieved from www.midss.ie

Glick, P. \& Fiske, S. T. (1996). The Ambivalent Sexism Inventory: Differentiating hostile and benevolent sexism. Journal of Personality and Social Psychology, 70, pp. 491-512.

Hantzi, A., Lampridis, E., Tsantila, K. \& Bohner, G. (2015).Validation of the Greek Acceptance of Modern Myths about Sexual Aggression (AMMSA) Scale: Examining Its relationships with sexist and conservative political beliefs International Journal of Conflict and Violence 9(1), pp.121-133.

Harris, R. J., Firestone, J. M., \& Vega, W. A. (2005). The interaction of country of origin, acculturation, and gender role ideology on wife abuse. Social Science Quarterly, 86, pp. 463-483.

Heise, L. L. (1998). Violence against women: An integrated, ecological framework. Violence Against Women, 4, pp.262-290.

Herrero, J., Torres, A., Rodríguez, F. J., \& Juarros-Basterretxea, J. (2017). Intimate partner violence against women in the European Union: The influence of male partners' traditional gender roles and general violence. Psychology of Violence, 7(3), pp. 385-394. https://doi.org/10.1037/vio0000099

Kenig, N. (2015). Exploration of Rape Myth Acceptance Predictors: The Role of Gender, Education, Sexism and Gender Norms. International Conference on Theory and Practice in Psychology - selected articles, 1/1, pp. 443-467.

Kenig, N. (2020). Conformity to Masculine Norms and Its Effects on Men's Well-Being. The Annual of the Faculty of Philosophy in Skopje, 73, 171-82. DOI:10.37510/godzbo2073171k

Kenig, N. \& Kostovski, D. (2019). Gender Differences in the Effects of Comprehensive Sexuality Education, Journal for Reattach Therapy and Developmental Diversities, Vol. 2, pp. 40-50.

Kirby, D. B. (2008). The Impact of Abstinence and Comprehensive Sex and STD/HIV Education Programs on Adolescent Sexual Behavior, Sexuality Research and Social Policy, 5(3), pp. 18-27. http://doi.org/10.1525/ srsp.2008.5.3.18

Lonsway, K.A. (1996). Preventing acquaintance rape through education: What do we know? Psychology of Women Quarterly. 20, pp. 229-265.

Lonsway, K. A., \& Fitzgerald, L. F. (1995). Attitudinal antecedents of rape myth acceptance: A theoretical and empirical reexamination. Journal of Personality and Social Psychology, 68(4), pp. 704-711.

Mahalik, J. R., Locke, B. D., Ludlow, L. H., Deimer, M. A., Scott, R. P., Gottfriend, M. (2003). Development of the Conformity to Masculine Norms Inventory. Psychology of Men \& Masculinity, 4, pp. 3-25.

Megías, J.L., Romero-Sánchez, M., Durán, M., Moya, M., \& Bohner, G. (2011). Spanish validation of the Acceptance of Modern Myths about Sexual Aggression scale. Journal of Psychology, 14(2), pp. 912-25. doi:10.5209/ rev_sjop.2011.v14.n2.37.PMID: 22059335 
McMahon, S., \& Farmer, G. L. (2011). An updated measure for assessing subtle rape myths. Social Work Research, 35, pp. 71-81. doi:10.1093/swr/35.2.71

Noar, S.M., and Morokoff, P.J. (2002). The relationship between masculinity ideology, condom attitudes, and condom use stage of change: A structural equation modeling approach. International Journal of Men's Health, 1(1), pp. 43-58.

O’Neil, J. M., \& Harway, M. (1997). A multivariate model explaining men's violence toward women: Predisposing and triggering hypotheses. Violence Against Women, 3, pp. 182-203

Parent, M.C. \& Moradi, B. (2010). Confirmatory Factor Analysis of the Conformity to Feminine Norms Inventory and Development of an Abbreviated Version: The CFNI-45. Psychology of Women Quarterly. 34(1), pp. 97-109. doi:10.1111/j.1471-6402.2009.01545

Parent, M. C., Moradi, B. (2010b). Confirmatory factor analysis of the Conformity to Masculine Norms Inventory and development of the CMNI-46. Psychology of Men \& Masculinity, 10, pp. 175-189.

Reidy, D. E., Brookmeyer, K. A., Gentile, B., Berke, D. S., and Zeichner, A. (2016). Gender Role Discrepancy Stress, High-Risk Sexual Behaviour, and Sexually Transmitted Disease. Archives of Sexual Behavior, 45(2), pp. 459-465.

Rollero, C. \& Tartaglia, S. (2019). The effect of sexism and rape myths on victim blame. Open Access. DOI:10.1007/s12119-018-9549-8

Ryan, K. M. (2011). The relationship between rape myths and sexual scripts: The social construction of rape. Sex Roles, 65 (11-12), 774-78

Santana, M.C., Raj, A., Deck, M.R., La Marche, A., Silverman, J.G. (2006). Masculine gender roles associated with increased sexual risk and intimate partner violence perpetration among young adult men. Journal of Urban Health. 83(4), 575-585. doi: 10.1007/s11524-006-9061-6.

UNESCO. (2016). Review of the evidence on sexuality education. Report to inform the update of the UNESCO International Technical Guidance on Sexuality Education, University of Oxford Centre for Evidence-Based Intervention. Paris, UNESCO

United Nations Educational, Scientific and Cultural Organization (UNESCO). Emerging Evidence: Lessons and Practice in Comprehensive Sexuality Education: A Global Review. Paris: UNESCO;2015. https://www.unfpa.org/sites/ default/files/pubpdf/CSE_Global_Review_2015.pdf.

Watson, L.C (2016). Exploring the Psychometric Properties of the Acceptance of Modern Myths about Sexual Aggression (AMMSA) Scale. Electronic Theses and Dissertations, Georgia Southern University, https://digitalcommons. georgiasouthern.edu/etd/1339

WHO (2021). Violence against women prevalence estimates, 2018. Global, regional and national prevalence estimates for intimate partner violence against women and global and regional prevalence estimates for non-partner sexual violence against women. Geneva: Department of Sexual and Reproductive Health and Research World Health Organization. 
